Article

\title{
New DC Grid Power Line Communication Technology Used in Networked LED Driver
}

\author{
Huipin Lin ${ }^{1}$, Jin $\mathrm{Hu}^{2}{ }^{2}$ Xiao Zhou ${ }^{1}$, Zhengyu Lu ${ }^{1}$ and Lujun Wang ${ }^{3, *}$ \\ 1 College of Electrical Engineering, Zhejiang University, Hangzhou 310027, China; \\ linhuipin@zju.edu.cn (H.L.); eezhoux@zju.edu.cn (X.Z.); eeluzy@cee.zju.edu.cn (Z.L.) \\ 2 Zhejiang Dabong Technology Co., Ltd., Hangzhou 311100, China; justinhu@dabong.com.cn \\ 3 Hubei Key Laboratory for High-Efficiency Utilization of Solar Energy and Operation Control of Energy \\ Storage System, Hubei University of Technology, Wuhan 430068, China \\ * Correspondence: wanglujun@zju.edu.cn; Tel.: +86-571-8795-1625
}

Received: 9 November 2018; Accepted: 15 December 2018; Published: 18 December 2018

check for updates

\begin{abstract}
In order to reduce the cost and improve the reliability, real-time performance, and installation convenience of remote-controlled light-emitting diode (LED) lighting systems, a networked LED driving technology based on the direct current (DC) grid power line carrier is proposed. In this system, an alternating current $(\mathrm{AC}) / \mathrm{DC}$ bus converter converts the mains into a DC bus with multiple distributed LED drive powers on the DC bus. The AC/DC bus converter receives the user's control command and modulates it into the DC bus voltage. The DC bus waveform changes to a square wave containing the high and low changes of the address information and command information. The LED drive power of the corresponding address receives energy from the DC bus and demodulates the commands, such as turning the lights on and off, dimming, etc., and performs the action. In order to make the waveform of the AC/DC bus converter have better rising and falling edge, this paper adopts the half-bridge topology with variable modal control. In the modulation process, the circuit works in buck mode and boost mode. Distributed LED drivers have DC/DC circuits and very simple demodulation circuits that dissipate energy and information from the DC bus. Through experiments, the technology not only simplifies the use of communication technology in application, but also reduces the application difficulty.
\end{abstract}

Keywords: PLC; bus converter; DC bus; LED driver

\section{Introduction}

With the rapid development of light-emitting diode (LED) technology, it is widely predicted that LED will become a new generation of lighting sources. Smart network control is a hot research topic in the field of LED lighting applications. In this application, multiple LED devices generally form an intelligent lighting system through a network, and the LED devices can usually be remotely controlled. In addition to road lighting for large-scale applications [1-4], most of these smart LED lighting systems are often used indoors or outdoors, and the scale is small [5-7].

Figure 1 shows a case for a small-scale LED smart lighting system, such as for commercial lighting, home lighting, landscape lighting, wall washers, high pole lights, etc. In these applications, the number of lamps is small, the distance between two adjacent LED light sources is relatively close, and a computer is typically used to remotely control turning on, turning off, and dimming the lights. 


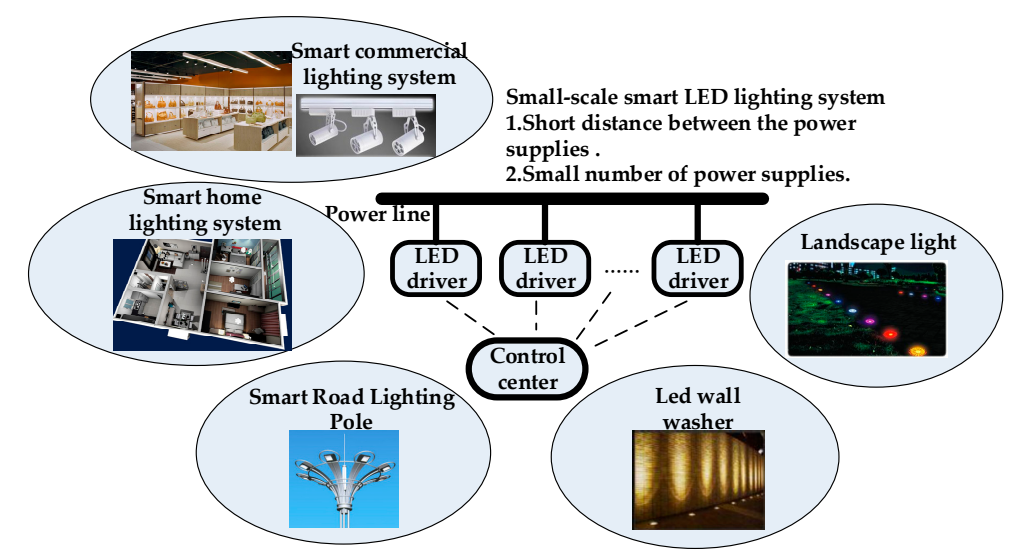

Figure 1. Common small networked control light-emitting diode (LED) smart lighting system.

In this small LED smart lighting system, communication between LED drivers is necessary to achieve control. Which communication technology is used determines the real-time performance and reliability of control in the system, while at the same time it also affects the cost, installation, and maintenance. Figure 2 shows descriptions of several common traditional lighting system communication schemes and their characteristics. These small LED lighting systems require a lower-cost solution, however, for 0-10 V, pulse-width modulation (PWM) control, digital addressable lighting interface (DALI) [8-14] and other remote-control schemes, and additional communication lines must be laid, which is unfavorable for installation and maintenance and costs more. Power line communication (PLC) [15-18] and the remote-control scheme of micropower wireless communication have advantages in practical applications due to the convenient installation. However, the cost of such a solution is still high, which is not conducive to its promotion. Table 1 lists the characteristics of these four options.

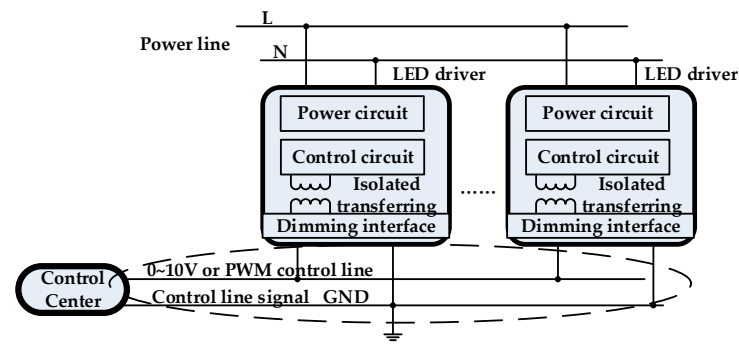

(a)

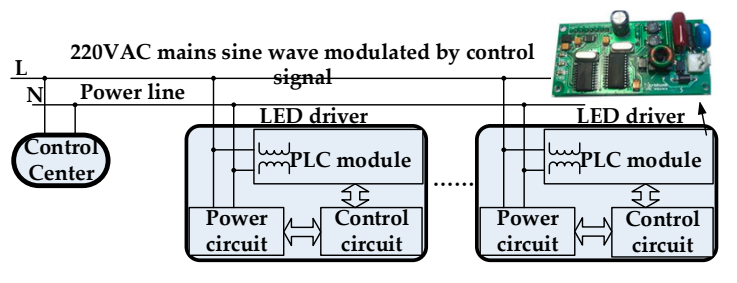

(c)

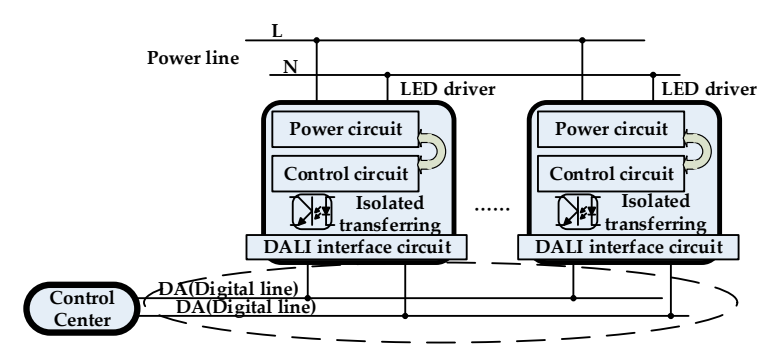

(b)

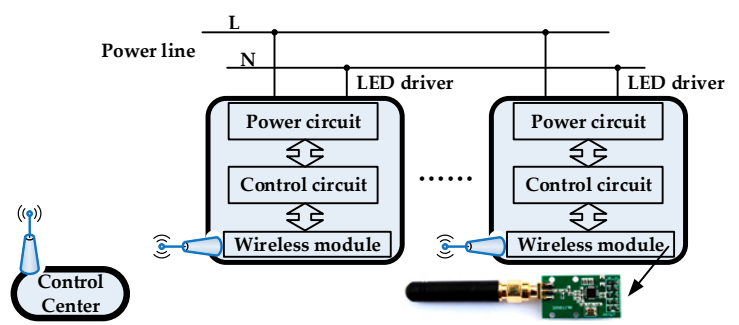

(d)

Figure 2. Common traditional remote control schemes: (a) 0-10 V or pulse-width modulation (PWM); (b) digital addressable lighting interface (DALI); (c) traditional alternating current (AC) grid power line communication; (d) traditional wireless. 
Table 1. Features of common traditional remote control schemes.

\begin{tabular}{cccc}
\hline Remote Control Scheme & Control Lines & Installation & Cost \\
\hline 0-10 V or PWM & 2 Lines & Complex & High \\
DALI & 2 Lines & Complex & High \\
Power line communication (PLC) & No & Very simple & High \\
Wireless & No & Simple & High \\
\hline
\end{tabular}

From the perspective of installation, the micropower wireless communication scheme needs to consider factors such as antenna and electromagnetic interference, which is greatly affected by space, and the PLC scheme is simpler. If the PLC solution can be further simplified, the cost and installation aspects are more advantageous. However, the traditional PLC solution is mainly used for alternating current (AC) mains grid, such as remote meter reading [19-21] and other applications. In the AC mains grid, PLC technology is relatively mature, and it is difficult to have major technological breakthroughs in a short period of time. It is difficult to reduce costs significantly. If power electronics can be used to transmit information while energy is being converted, the PLC module in Figure 2c may no longer be needed and the system cost may be greatly reduced. In the AC mains grid, since the existing transmission and distribution schemes are already very mature, it is difficult to implement communication using power electronics technology. However, if a direct current (DC) grid or an AC microgrid is constructed, it is easy to realize communication while transmitting DC power in the grid.

The LED lighting system based on DC grid has received attention. In [22] an indoor LED smart lighting system was proposed based on DC grid, as shown in Figure 3. The system uses an AC/DC converter to change AC mains to DC bus, and a number of distributed DC/DC LED drivers are connected to the DC bus. The system implements intelligent control and energy saving, but with the DALI communication protocol, a separate control line is still required. A similar DC bus architecture is also proposed in [23].



(a)

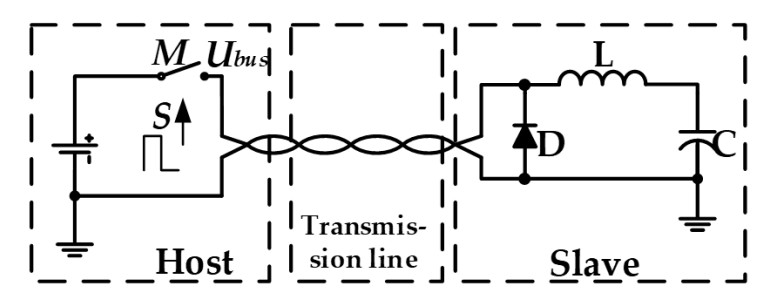

(b)

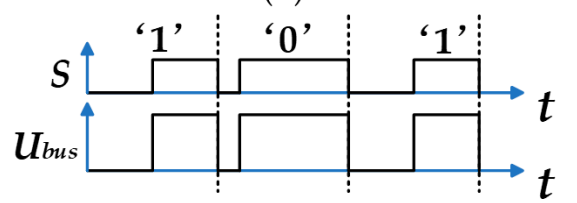

(c)

Figure 3. Traditional LED lighting system technology based on direct current (DC) grid: (a) Traditional networked LED system based on DC grid; (b) Traditional DC grid PLC technology; (c) the drive signal waveform of host switch $M$ and the waveform of bus voltage $U_{b u s}$.

PLC in the DC grid has also been studied in recent years, and this technology can eliminate the control line in Figure 3a. A novel DC PLC solution was proposed in [24], which is cheaper for small-scale power line communication applications. Figure 3b,c show the basic principle, as shown in the waveform: when the host switch $M$ is turned on, the voltage $U_{\text {bus }}$ goes high, representing logic 1 . When switch $\mathrm{M}$ is turned off, voltage $\mathrm{U}_{\text {bus }}$ goes low, representing logic 0 . The circuit works in the structure of the buck circuit, and the energy is stored in the output capacitor $C$ of the slave. The change of the voltage $U_{\text {bus }}$ during the energy transfer is detected by the slave, and the simultaneous transmission of energy and signals is realized. However, due to the influence of parasitic parameters 
on the transmission line, the switching device of the circuit is subject to greater voltage stress than the conventional buck circuit.

Some papers have proposed DC PLC schemes [25-29], but they all need additional communication lines. They bring larger parasitic parameters and cause front-stage metal-oxide-semiconductor field effect transistor (MOSFET) high current spikes and damage when the MOSFETs are working at high frequency. So the front-stage MOSFETs need better performance requirements. They are more complicated if used for LEDs.

In order to overcome the problems of the above two types of research, this paper proposes a remotely controlled LED lighting system similar to the DC grid structure of Figure 3a, but with the control line omitted. In this system, an AC/DC bus converter converts the mains into a DC bus, and multiple distributed LED drivers are connected to the DC bus. The AC/DC DC bus converter receives the user's control command and modulates it into the DC bus voltage. The DC bus waveform changes to a square wave containing the high and low changes of the address information and the command information. The LED driving power source corresponding to the address receives energy from the DC bus and demodulates commands such as turning on the light, turning off the light, dimming, etc. In order to make the waveform of AC/DC DC bus converter have better rising and falling edge, this paper adopts the half-bridge topology with variable modal control. In the modulation process, the circuit works in buck mode and boost mode. Distributed LED drivers have DC/DC circuits and very simple demodulation circuits that dissipate energy and information from the DC bus.

With this remote control scheme, the following problems are solved:

1. Compared with 0-10 V, PWM, and DALI controlled systems, the communication line is omitted.

2. The traditional AC mains PLC module is saved, and the signal transceiving function is realized by power electronic technology.

3. Compared with the existing DC PLC technology, the influence of power line on communication is greatly reduced, and communication reliability is improved.

Compared with the conventional schemes described above, this scheme is simpler and costs less. This paper verifies the feasibility of this technology by experiments.

\section{Light-Emitting Diode (LED) Networked Drive Technology Based on Direct Current (DC) Grid Power Line Communication (PLC)}

\subsection{System Architecture}

The specific architecture of the LED lighting system proposed in this paper is shown in Figure 2a. It includes a control center, an AC/DC bus converter, a DC bus, and a distributed LED driver. The control center sends control signals to the LEDs to the AC/DC bus converter. This type of technology is relatively mature and can be used for wireless communication such as a General Packet Radio Service (GPRS). The bus converter converts the AC mains into a DC bus voltage $\mathrm{v}_{\text {bus }}$ with a maximum value of $48 \mathrm{~V}$, and modulates the information to be transmitted into the bus voltage to make it high and low DC levels. The high voltage represents logic 1 and the low voltage represents logic 0 . The DC bus is the transmission line, and the distributed LED driver as the load extracts energy from the DC bus drives the LED light source and demodulates the signal from the bus.

\subsection{New DC Power Line Carrier Energy and Information Demodulation Principle}

The master/slave communication mode is between the AC/DC bus converter and the distributed LED driving power source. The former is the master, the latter is the slave, and the DC bus is used as the medium to provide energy and transfer information to the slave.

The LED driver power supply includes three parts: an energy demodulation circuit, a signal demodulation circuit, and a DC/DC converter. The energy and signal demodulation circuits are both half-wave rectification circuits, as shown in Figure 4a. Taking the $j$ th LED driving power supply in 
Figure $4 \mathrm{a}$ as an example, the energy demodulating circuit is connected in series with the DC/DC converter, and the output of the signal demodulating circuit is connected to the control circuit of the $\mathrm{DC} / \mathrm{DC}$ converter. The difference between the two is that the energy demodulation circuit's output capacitance $C_{p j}$ has a large capacitance value. When the $v_{\text {bus }}$ voltage is 0 , the energy of the DC/DC converter of the latter stage can still be supplied for a period of time, that is, $\mathrm{v}_{\mathrm{pj}}$ is maintained within the allowable ripple voltage range to keep the circuit working properly.It remains stable for a long time; the output capacitance value $C_{\mathrm{sj}}$ of the latter is small. When the $v_{\text {bus }}$ voltage is $0, v_{\mathrm{sj}}$ is discharged through the resistor $R_{s j}$ and quickly falls to 0 , so that the change of $v_{s j}$ is consistent with the change of $\mathrm{v}_{\text {bus }}$. Taking the waveform in Figure $4 \mathrm{~b}$ as an example, the process of demonstrating a remote dimming operation has the following stages:

$t_{1}$ : The output of the AC/DC bus converter is $48 \mathrm{~V} \mathrm{DC}$, and the load is full power. During this time, the bus converter receives the $j$ th LED drive power dimming command from the control center to address $A_{j}$.

$t_{1}-t_{2}$ : The bus converter modulates the information into the DC bus, and the bus voltage $v_{\text {bus }}$ changes to the waveform shown in Figure $4 \mathrm{~b}$. All LED drive power supplies receive the command, but only the $j$ th addresses $A_{j}$. The drive power source executes the dimming command. The total power on the busbar drops from time $t_{3}$ when the command is executed. The communication protocol can adopt a mature scheme such as RS232 or a custom scheme.

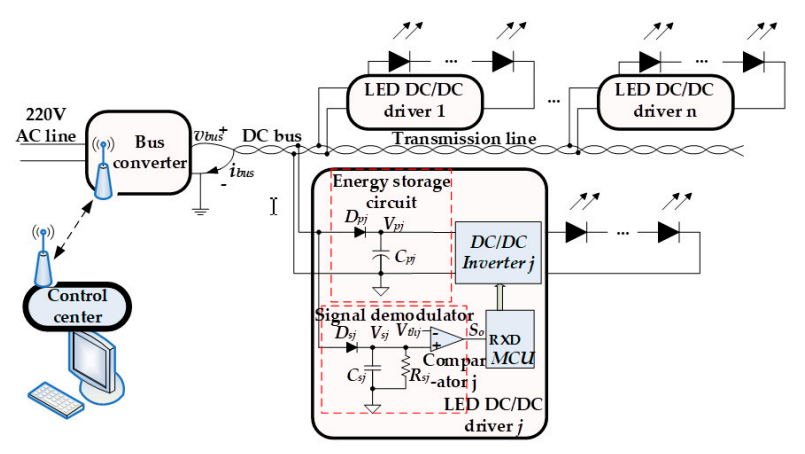

(a)

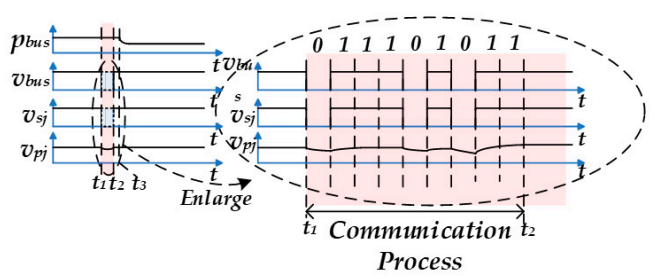

(b)

Figure 4. Networked control LED system based on DC grid PLC: (a) system architecture diagram; (b) system key waveforms.

\subsection{Working Principle of Bus Converter Based on Variable Modal Control}

The key device for system energy and information modulation is the AC/DC bus converter. Figure $5 \mathrm{a}, \mathrm{b}$ shows a schematic diagram and the corresponding buck and boost working modes. The circuit is divided into two stages. The first stage is a power factor correction (PFC) circuit to achieve a high power factor. The output is a fixed DC voltage $V_{g}$ as the input of the second stage.

The second stage is a half-bridge circuit, the output is a DC bus, and the DC bus is connected to several LED driving power sources. The LED driving power can be regarded as the active load of the second-stage half-bridge circuit, and the total equivalent power is $\mathrm{P}_{\mathrm{LED}} . \mathrm{D}_{1}$ and $\mathrm{D}_{2}$ are body diodes of the half-bridge circuit MOSFETs $\mathrm{M}_{1}$ and $\mathrm{M}_{2}$, respectively. The control circuit has a single-chip microcomputer (MCU), which samples the output voltage $\mathrm{v}_{\text {bus }}$ through the sampling resistors $\mathrm{R}_{1}$ and $R_{2}$, and $R_{\text {Boostcs }}$ and $R_{\text {Buckcs }}$ are sampling resistors, respectively sampling the inductor currents in boost and buck modes.

In different situations, the half-bridge circuit operates in buck mode or boost mode. Figure $5 \mathrm{c}$ shows the main waveforms of these two modes.

$t_{0}-t_{1}$ : The AC/DC bus converter does not send a signal to the LED driver, and its output voltage is constant DC $48 \mathrm{~V}$. The upper tube $\mathrm{M}_{1}$ is operated as a high-frequency switch, the lower tube $\mathrm{M}_{2}$ is stopped, the half-bridge circuit operates in buck mode as shown in Figure 5a, and the body diode 
$D_{2}$ of the $M_{2}$ acts as a freewheeling diode of the buck circuit. The bus converter charges capacitor $C_{2}$, which supplies energy to the distributed LED driver.

$t_{1}-t_{11}$ : The bus converter receives the command and modulates it into the bus voltage $v_{\text {bus }}$, causing it to change to high and low DC levels. Defining the signal $S_{\text {in }}$ passed, when $S_{\text {in }}$ is logic 0 , the bus converter operates in boost mode, and when $S_{\text {in }}$ is logic 1 , the bus converter operates in buck mode. When in boost mode, the upper tube $M_{1}$ stops working, and $M_{2}$ operates as a high-frequency switch. The body diode $\mathrm{D}_{1}$ of the $\mathrm{M}_{1}$ operates as a freewheeling diode of the boost circuit, as shown in Figure $5 \mathrm{~b}$. At this time, the energy on the bus voltage $\mathrm{v}_{\text {bus }}$ across the output capacitor $\mathrm{C}_{2}$ is quickly transferred to the half-bridge input capacitor $C_{1}$, and the level rapidly drops to zero. Since the LED driving power supply in Figure $4 \mathrm{a}$ has diodes $\mathrm{D}_{\mathrm{pj}}$ and $\mathrm{D}_{\mathrm{sj}}$, the change in bus voltage does not affect the energy and signal demodulating circuits in the LED driving power supply.

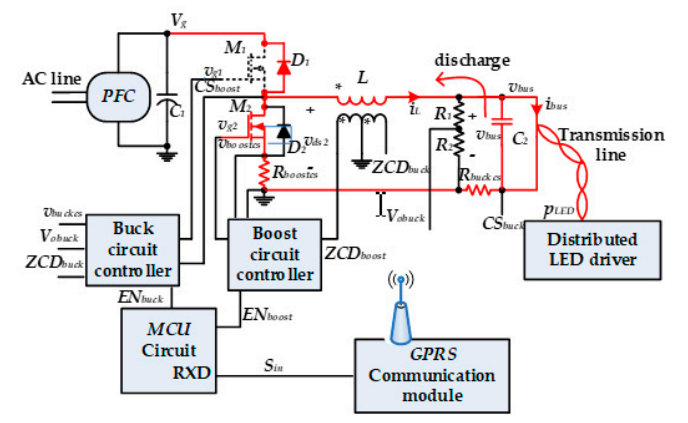

(a)

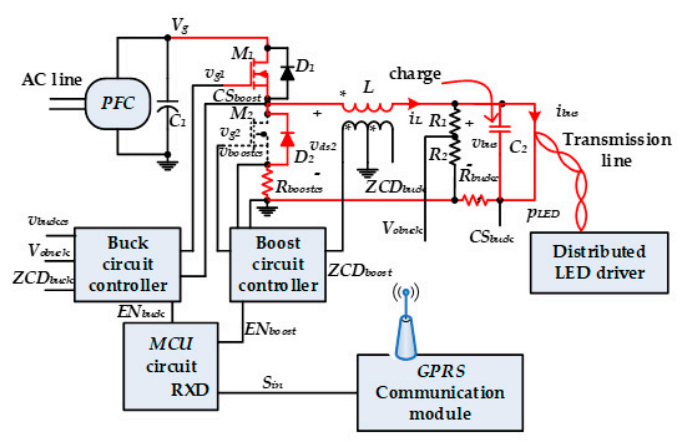

(b)

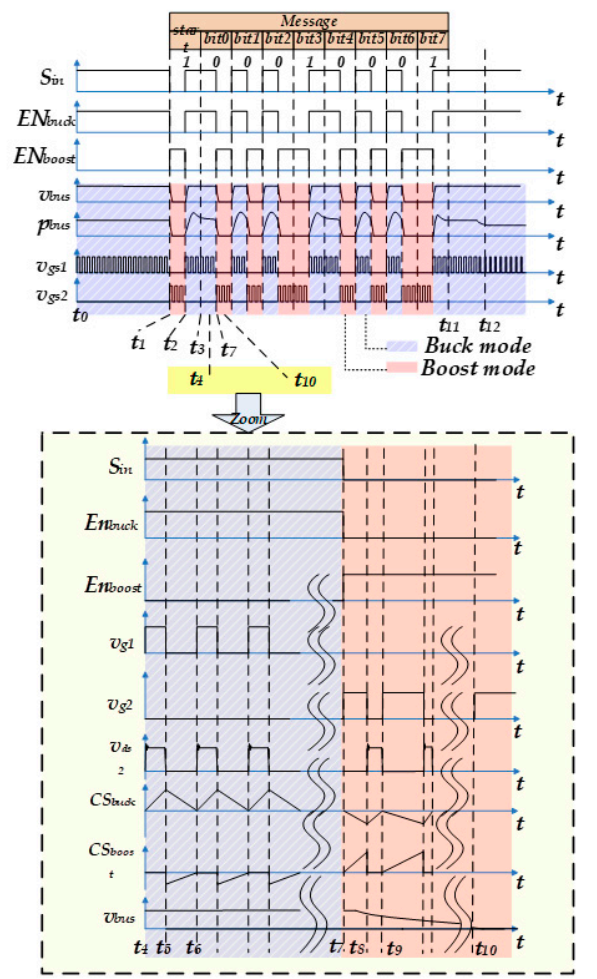

(c)

Figure 5. Work principles of bus converter: (a) circuit principle of buck mode; (b) circuit principle of boost mode; (c) working waveform.

The half-bridge circuit adopts different working modes, so that in buck mode, the bus voltage $\mathrm{v}_{\text {bus }}$ across capacitor $\mathrm{C}_{2}$ can rise rapidly; in boost mode, the bus voltage $\mathrm{v}_{\text {bus }}$ across capacitor $\mathrm{C}_{2}$ can be quickly reduced. There are three advantages to using this method of variable mode control:

(1) The bus voltage $v_{\text {bus }}$ changes rapidly, which is beneficial to improve the signal transmission speed and facilitate the operation of the signal demodulation circuit in the LED driver.

(2) If there is no boost mode, the bus converter should make the busbar low voltage and can only rely on the load to discharge naturally. However, in the case of light load of the bus converter, especially when the load is turned off, when the bus converter is equivalent to no-load, the DC bus voltage $\mathrm{v}_{\text {bus }}$ drops to 0 , which takes a long time, and the energy storage of the LED driving power capacitor $\mathrm{C}_{\mathrm{pj}}$ may not last so long. Boost mode allows the bus to quickly go low under light load conditions.

(3) Since boost mode feeds back the energy of output capacitor $C_{2}$ to input capacitor $C_{1}$, it can be used again next time, so the energy utilization efficiency in the communication process is higher. 
$t_{12}$ : After the drive power supply executes the dimming command, the total $p_{b u s}$ power on the bus is reduced.

As shown in Figure 5a,b, it is divided into two modes, buck and boost. Due to the poor reverse recovery performance of the body diode of the MOSFET, the circuit uses boundary current mode (BCM) regardless of buck or boost mode. The control circuits of both modes are controlled by ST L6562. In buck mode, $\mathrm{M}_{2}$ is always off and its body diode $\mathrm{D}_{2}$ operates as a freewheeling diode of the buck circuit. In the main circuit, the signal $\mathrm{ZCD}_{\text {Buck }}$ that controls M1 turn-on, the peak current signal $\mathrm{CS}_{\text {Buck }}$ that controls M1 turn-off, and the output voltage signal $\mathrm{V}_{\text {oBuck }}$ are sampled into the buck circuit controller. In boost mode, $\mathrm{M}_{1}$ is always off, and its body diode $\mathrm{D}_{1}$ acts as a freewheeling diode of the boost circuit. In the main circuit, the signal $\mathrm{ZCD}_{\text {Boost }}$ that controls $\mathrm{M}_{2}$ turn-on and the peak current signal $\mathrm{CS}_{\text {Boost }}$ that controls $\mathrm{M}_{2}$ turn-off are sampled into the boost control circuit.

In the $t_{4}-t_{10}$ time of Figure $5 c$, the specific working waveforms of the two working modes are given. At time $t_{4}$, the transmitted signal $S_{\text {in }}$ is still high, $\mathrm{EN}_{\text {Buck }}$ is high, and $\mathrm{EN}_{\text {Boost }}$ is low, indicating that the circuit is in buck mode, $\mathrm{M} 1$ is operational, $\mathrm{M}_{2}$ is disabled, and its drive signal $\mathrm{V}_{\mathrm{g} 2}$ is always low. The body diode $\mathrm{D}_{2}$ of $\mathrm{M}_{2}$ operates as a freewheeling diode of the buck circuit. The energy flow of the circuit flows from capacitor $C_{1}$ to $C_{2}$, as shown in Figure 5 a.

$$
\mathrm{v}_{\mathrm{g}}-\mathrm{v}_{\text {bus }}=\mathrm{L} \frac{\mathrm{i}_{\mathrm{Lpk}}}{\mathrm{t}_{5}-\mathrm{t}_{4}}
$$

where $i_{L p k}$ is the peak value of the inductor current during this period.

$t_{5}-t_{6}: M_{1}$ is turned off, the inductor current drops, the body diode $D_{2}$ of $M_{2}$ continues to flow, $\mathrm{CS}_{\text {Boost }}$ is negative voltage, and the half-bridge midpoint voltage $\mathrm{V}_{\mathrm{ds} 2}$ is low. The voltage and current in the circuit satisfy Equation (2), and the circuit gain relationship still satisfies the law of the buck circuit, as in Equation (3).

$$
\begin{gathered}
\mathrm{v}_{\text {bus }}=\mathrm{L} \frac{\mathrm{i}_{\mathrm{Lpk}}}{\mathrm{t}_{6}-\mathrm{t}_{5}} \\
\mathrm{v}_{\text {bus }}=\frac{\mathrm{t}_{5}-\mathrm{t}_{4}}{\mathrm{t}_{6}-\mathrm{t}_{4}} \cdot \mathrm{v}_{\mathrm{g}}
\end{gathered}
$$

$t_{6}-t_{7}$ : The circuit repeats the working process of the $t_{4}-t_{6}$ switching cycle until time $t_{7}$, the transmission signal $\mathrm{S}_{\text {in }}$ becomes low level, $\mathrm{EN}_{\text {Buck }}$ is low, and $\mathrm{EN}_{\text {Boost }}$ is high, indicating that the circuit is in boost mode; $M_{2}$ can work, $M_{1}$ is disabled, and its drive signal $V_{g 1}$ is always low. The body diode $D_{1}$ of $M_{1}$ operates as a freewheeling diode of the boost circuit. The energy flow of the circuit flows as shown in Figure $5 \mathrm{~b}$ from capacitor $\mathrm{C}_{2}$ to $\mathrm{C}_{1}$.

$t_{7}-t_{8}: M_{2}$ is turned on, the inductor current rises in the reverse direction, $C_{\text {Buck }}$ is negative voltage, and the half-bridge midpoint voltage $\mathrm{V}_{\mathrm{ds} 2}$ is low. The voltage and current in the circuit satisfy the law of the general boost circuit, as shown in Equation (4).

$$
\mathrm{v}_{\text {bus }}=\mathrm{L} \frac{-\mathrm{i}_{\text {Lpk }}}{\mathrm{t}_{8}-\mathrm{t}_{7}}
$$

$t_{8}-t_{9}: M_{2}$ is turned off, the inductor current drops, the body diode $D_{1}$ of $M_{1}$ continues to flow, $\mathrm{CS}_{\text {Buck }}$ is negative voltage, and the half-bridge midpoint voltage $\mathrm{V}_{\mathrm{ds} 2}$ is high. The voltage and current in the circuit satisfy Equation (5), and the circuit gain relationship still satisfies the law of the boost circuit, as in Equation (6).

$$
\begin{gathered}
\mathrm{v}_{\mathrm{g}}-\mathrm{v}_{\text {bus }}=\mathrm{L} \frac{-\mathrm{i}_{\mathrm{Lpk}}}{\mathrm{t}_{9}-\mathrm{t}_{8}} \\
\mathrm{v}_{\mathrm{g}}=\frac{\mathrm{t}_{9}-\mathrm{t}_{7}}{\mathrm{t}_{9}-\mathrm{t}_{8}} \cdot \mathrm{v}_{\text {bus }}
\end{gathered}
$$

$t_{9}-t_{10}$ : The circuit repeats the working process of the $t_{7}-t_{9}$ switching cycle until $t_{10}$, because the voltage on $C_{2}$ is already very low, meaning that most of the energy on $C_{2}$ is fed back to $C_{1}$. 
The working principle of the bus converter described above is that the modal control of the circuit realizes the transformation of the high and low levels on capacitor $C_{2}$ to achieve the purpose of simultaneously transmitting energy and information.

\subsection{Distributed LED Drive Power DC/DC Converter Working Principle}

The distributed LED drive power directly drives the light source and demodulates the communication information from the DC bus. The driving power source is divided into an energy demodulating circuit, an information demodulating circuit, and a DC/DC converter. The principles of the first two have already been introduced. Here, the working principle of the DC/DC converter is introduced.

In theory, there are many solutions for implementing the DC/DC converter of the driving power supply. This paper introduces the principle of demodulation energy and information by taking the buck circuit as an example. Figure 6 shows the schematic and key waveforms of the DC/DC converter in the distributed drive power supply of Figure 4a.

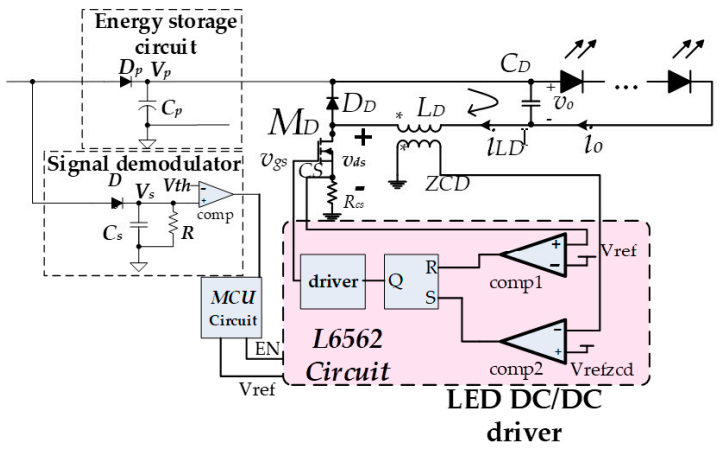

(a)



(b)

Figure 6. Principle of distributed drive power DC/DC converter: (a) schematic diagram; (b) key waveform.

The DC/DC converter uses a buck circuit and operates in a critical mode. Due to the critical mode, the output current $i_{o}$ and the peak value $i_{L D p k}$ of the inductor current $i_{L D}$ satisfy the following relationship:

$$
\mathrm{i}_{\mathrm{o}}=\frac{1}{2} \mathrm{i}_{\mathrm{LDpk}}
$$

According to Equation (7), the output current $i_{O}$ can be made constant by controlling $i_{\text {LDpk }}$ to be constant. The control circuit is implemented by chip L6562. The specific working process is as follows:

$t_{1}-t_{2}$ : The enable signal EN given by the microcontroller allows the DC/DC converter to operate. The MOSFET MD is turned on and the inductor current rises. The voltage and current in the circuit meet the following equation:

$$
\mathrm{V}_{\mathrm{p}}-\mathrm{v}_{\mathrm{o}}=\frac{\mathrm{L}_{\mathrm{d}} \cdot \mathrm{i}_{\mathrm{LDpk}}}{\mathrm{t}_{2}-\mathrm{t}_{1}}
$$

$t_{2}-t_{3}$ : At time $t_{2}$, the voltage on the sampling resistor $R_{C S}$ reaches the threshold value $V_{\text {ref }}$ of comparator comp1, comp1 gives a positive level, and the output level of the RS flip-flop becomes low, so that the $M_{D}$ is turned off. At this time, the diode $D_{D}$ starts freewheeling, and the inductor current decreases. At time $t_{3}$, since the inductor current drops to zero, the $\mathrm{Z}_{\mathrm{CD}}$ voltage drops, and the comparator comp2 output is high, causing the RS flip-flop output to be high, and the drive circuit starts driving the $\mathrm{M}_{\mathrm{D}}$ to conduct and begins to enter the next switching cycle. During this period, the voltage and current in the circuit satisfy Equation (9), and the circuit gain relationship still satisfies the law of the buck circuit, as in Equation (10). 


$$
\begin{gathered}
\mathrm{v}_{\mathrm{o}}=\frac{\mathrm{L}_{\mathrm{d}} \cdot \mathrm{i}_{\mathrm{LDpk}}}{\mathrm{t}_{3}-\mathrm{t}_{2}} \\
\mathrm{v}_{\mathrm{o}}=\frac{\mathrm{t}_{2}-\mathrm{t}_{1}}{\mathrm{t}_{3}-\mathrm{t}_{1}} \cdot \mathrm{V}_{\mathrm{p}}
\end{gathered}
$$

The $t_{3}-t_{4}$ circuit repeats the switching cycle state of $t_{1}-t_{3}$. It should be pointed out that $V_{\text {ref }}$ is given by the single-chip circuit and $V_{\text {ref }}$ changes, according to Equation (7); the output current also changes.

$t_{4}-t_{7}$ : The single-chip circuit receives the dimming command from the bus converter, reduces the $\mathrm{V}_{\text {ref }}$ voltage, and reduces the output current $\mathrm{i}_{\mathrm{o}}$ of the DC/DC converter.

$t_{7}$ : The single-chip circuit receives the shutdown command from the bus converter, turns the enable signal EN to low, the DC/DC converter stops working, and the output current is zero.

Through the working principles described above, the distributed LED driving power supply can drive the LED load according to the command sent by the bus converter.

\section{Experimental Verification}

The principles of system operation were introduced in the previous section, and the working process of the bus converter and distributed LED driver power supply is analyzed in detail. In order to verify the technology mentioned in this section, this paper establishes a verification system as shown in Figure 4a. The physical diagram is shown in Figure 7. System parameters are shown in Table 2.

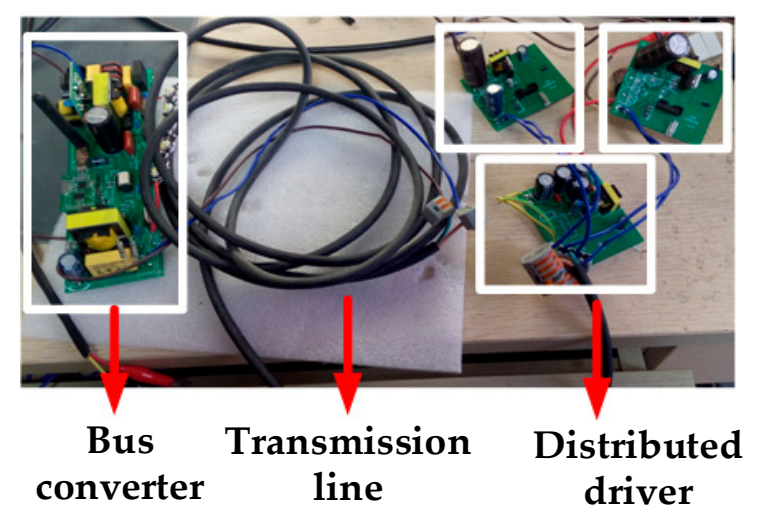

Figure 7. Picture of demo system.

Table 2. System key parameters.

\begin{tabular}{ccc}
\hline & Quantity & 1 \\
& Input voltage & $220 \mathrm{~V} / 50 \mathrm{~Hz}$ \\
Bus Converter & PFC voltage & $400 \mathrm{~V}$ \\
& Output voltage maximum & $48 \mathrm{~V}$ \\
& Total power maximum & $30 \mathrm{~W}$ \\
& Communication baud rate & 9600 \\
\hline \multirow{3}{*}{ Distributed LED Driver } & Quantity & 3 \\
& Single rated power & $10 \mathrm{~W}$ \\
& & $3 \mathrm{~W} \mathrm{LED}$ \\
& Single load structure & 3 series \\
& & 3 parallel \\
& Single load rated current & $700 \mathrm{~mA}$ \\
\hline
\end{tabular}

\subsection{Bus Converter Working Principle Verification}

The main task of the bus converter is to convert the AC mains into the bus of the DC grid. During the transition, the DC grid output voltage is modulated into a signal that is communicated to the distributed LED drive power source, allowing both signal and energy to be delivered simultaneously. This experiment mainly verifies this function. 
Figure 8 shows the input and output waveforms of the bus converter. It can be seen that under the $220 \mathrm{~V}$ AC mains, the bus converter converts it into a $48 \mathrm{~V} \mathrm{DC}$ bus $\mathrm{v}_{\text {bus. }}$. After the communication signal $S_{\text {in }}$ is modulated into the $v_{\text {bus }}$, the $S_{\text {in }}$ changes, and the $v_{\text {bus }}$ also changes in the same waveform to achieve simultaneous transmission of energy and information. Due to the presence of the PFC circuit, the power factor is approximately 1 , and the input voltage and current waveforms are approximately the same.

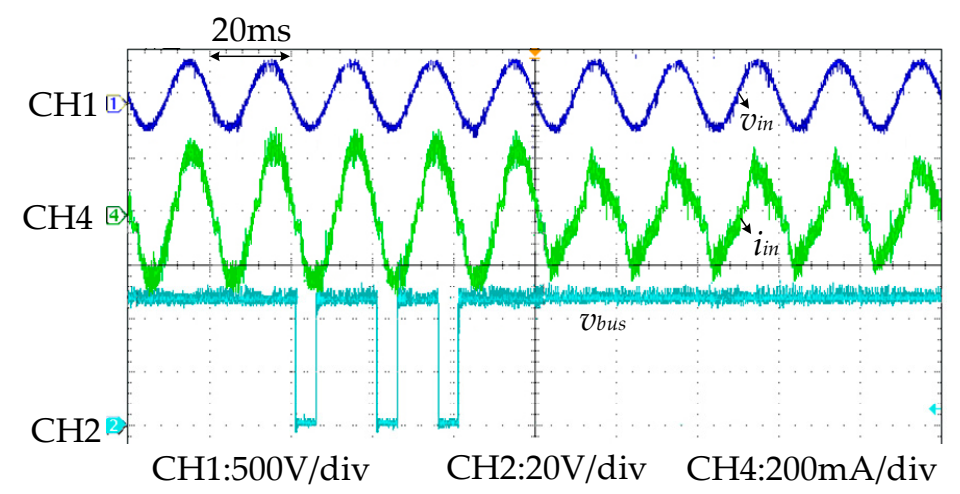

Figure 8. Input and output waveforms of bus converter.

According to the above description, when the DC bus voltage $\mathrm{v}_{\text {bus }}$ is high, the bus converter is in buck mode, and the output $\mathrm{v}_{\mathrm{bus}}$ is high. When $\mathrm{v}_{\mathrm{bus}}$ is low, in order to quickly reduce the voltage of the bus converter output capacitor $C_{2}$, the bus converter goes into boost mode, so that the $C_{2}$ energy is quickly transferred to the bus converter input capacitor $C_{1}$ for continued use in the next cycle. Figure 9 shows the main waveforms of the modal transformation. The pass signal $S_{\text {in }}$ is the same as the enable signal of buck mode. It can be seen from the waveform that in steady state, the bus converter operates in buck mode, the signal $S_{\text {in }}$ is high, the drive $V_{\mathrm{g} 1}$ of the upper tube $\mathrm{M}_{1}$ is working, the drive $\mathrm{V}_{\mathrm{g} 2}$ of the lower tube $\mathrm{M}_{2}$ is low, and the output voltage $\mathrm{v}_{\mathrm{o}}$ is constantly $48 \mathrm{~V}$. When the bus converter receives the command, it modulates the signal $S_{\text {in }}$ into the output bus, causing it to become a square wave with the same high and low conversion as $S_{i n}$. At this time, buck and boost modes of the bus converter are switched according to the transmission signal.

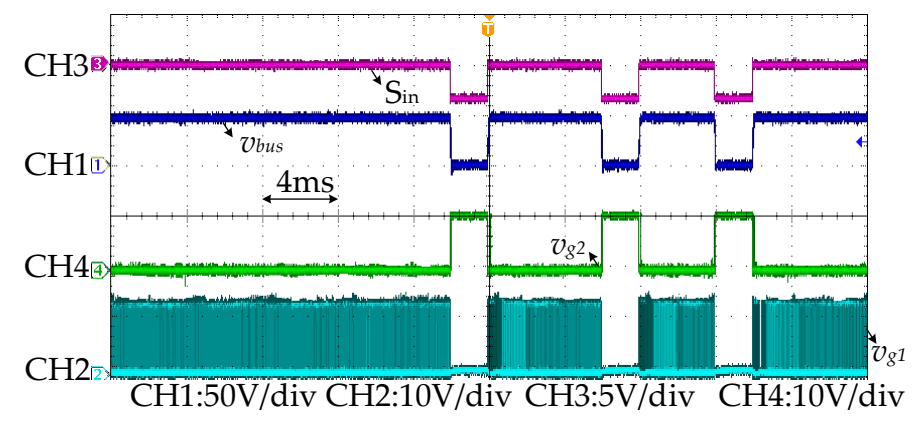

Figure 9. Main waveforms of bus converter during steady state and communication.

The output transformer of the bus converter is continuously charged and discharged during the signal modulation process. It is essentially the energy flow relationship between the input capacitance $C_{1}$ of the bus converter and the output capacitor $C_{2}$. Figure 10 shows the experimental relationship of energy flow. It can be seen from Figure 10 that in buck mode, the buck sampling resistor voltage $\mathrm{v}_{\text {Buckss }}$ is positive, the boost sampling resistor voltage $\mathrm{v}_{\text {Boostcs }}$ is negative, and the bus converter output capacitor $C_{2}$ is charged. In boost mode, the buck sampling resistor voltage $v_{\text {Buckss }}$ is negative, the boost sampling resistor voltage $v_{\text {Boostcs }}$ is positive, and the bus converter output capacitor $C_{2}$ energy is transferred to the input capacitor $\mathrm{C}_{1}$. 


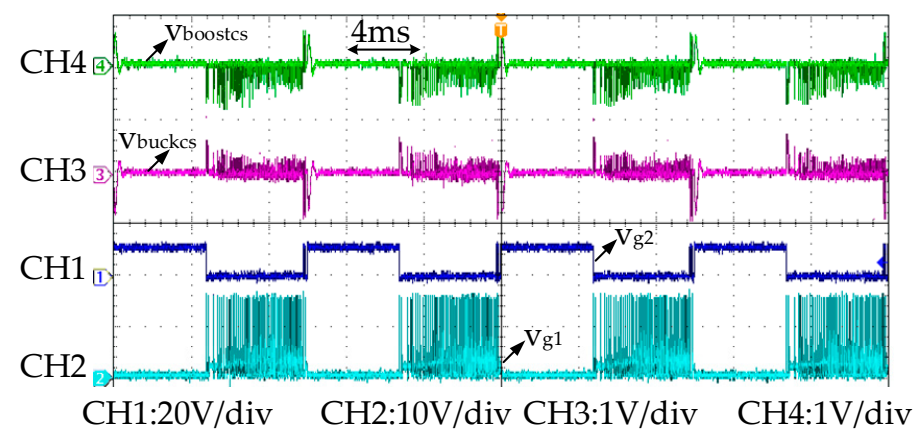

Figure 10. Energy flow relationship in the process of bus converter modal transformation.

As mentioned above, since the bus converter needs to use a body diode of a MOSFET of half-bridge topology as a freewheeling tube in either buck or boost mode, the reverse recovery capability of the MOSFET body diode is poor, in order to reduce this. The effect is that the circuit uses a critical mode. Figure 11a,b shows the key waveforms of the bus converter in buck and boost mode during communication. In buck mode, the sampling resistor voltage $\mathrm{v}_{\text {Buckss }}$ and the half-bridge midpoint voltage $\mathrm{v}_{\mathrm{ds} 2}$ are visible, and the circuit operates in a critical mode, avoiding the loss caused by the reverse recovery of the body diode $\mathrm{D}_{2}$ of the lower tube $\mathrm{M}_{2}$. In boost mode, the sampling resistor voltage $\mathrm{v}_{\text {boostcs }}$ and the half-bridge midpoint voltage $\mathrm{v}_{\mathrm{ds} 2}$ are visible, and the circuit operates in a critical conduction mode, avoiding the loss caused by the reverse recovery of the body diode $\mathrm{D}_{1}$ of the upper MOSFET $\mathrm{M}_{1}$. This experiment verifies the working principle of the bus converter.

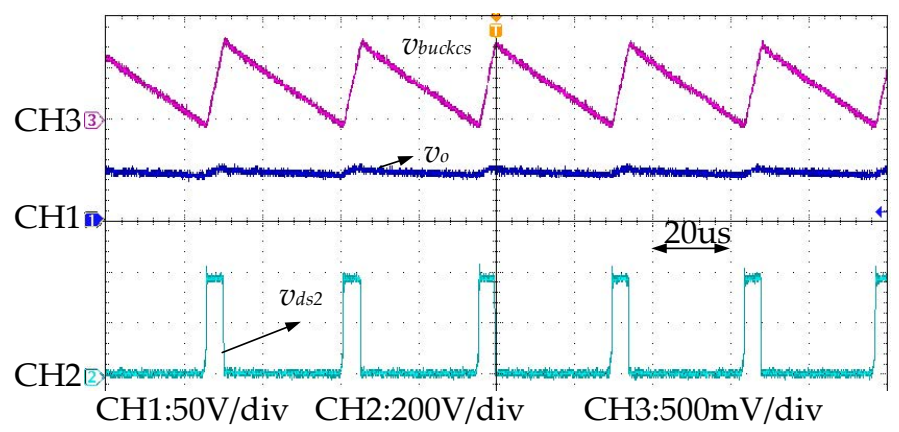

(a)



(b)

Figure 11. Critical conduction mode waveforms of the bus converter under (a) buck mode and (b) boost mode.

\subsection{Distributed LED Driver Power Supply Working Principle Verification}

The main task of the distributed LED drive power source is to receive the energy of the DC bus and demodulate the information. This experiment mainly verifies this function. 
Figure 12 shows the main waveforms of the energy and information demodulation of the distributed LED driver power supply during communication. It can be seen from Figure 6 that when the enable signal EN is 1 , the MOSFET $M_{D}$ starts to work. As shown in Figure 12, $v_{g s}$ is a high-low level transition of the driving signal of the MOSFET $M_{D}$, enabling the distributed LED driver to operate, so that the bus voltage $\mathrm{v}_{\mathrm{bus}}$ is high level. At this time through the modulation and demodulation of the signal circuit, so that $\mathrm{v}_{\mathrm{s}}$ is also high level, and in the energy circuit, $\mathrm{v}_{\mathrm{p}}$ is also high level output. When the enable signal EN is 0 , the MOSFET $M_{D}$ stops working. At this time, the driving signal $v_{g s}$ of $M_{D}$ is kept low. At this time, in the signal circuit, $v_{s}$ is also low, and in the energy circuit, due to the capacitance of $C_{p}$, as shown in the figure, is slightly dropped and can be maintained within the allowable ripple voltage range to keep the circuit working properly.

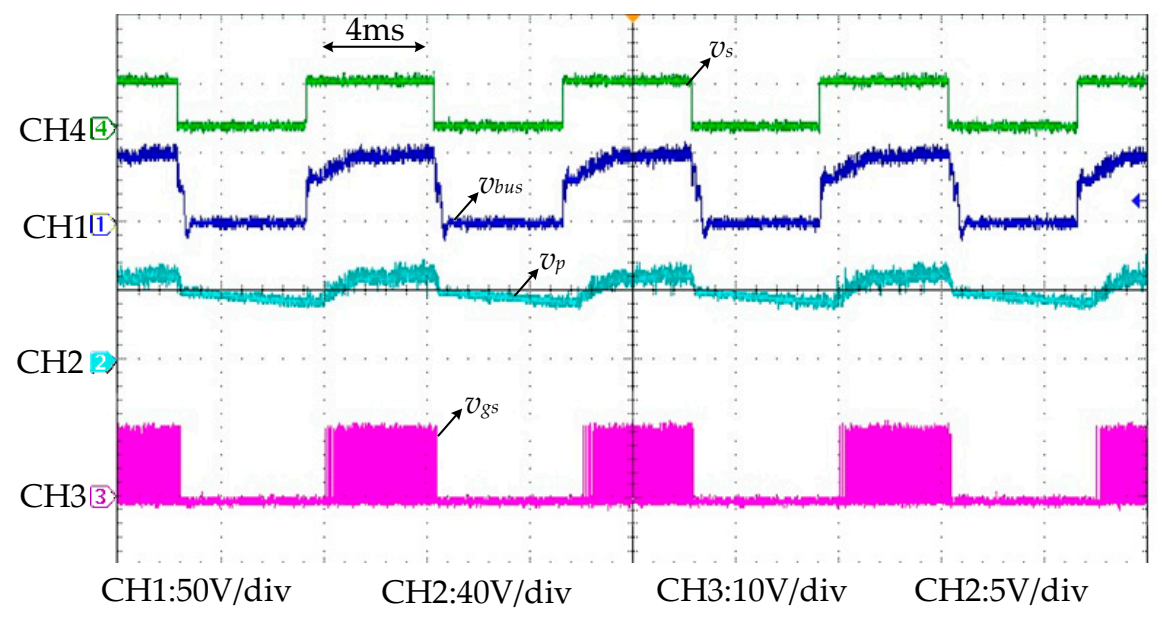

Figure 12. Distributed LED drive power energy and information.

In this section, the distributed LED driver power supply uses a critical conduction mode buck circuit, and the output current $i_{\mathrm{o}}$ is a constant current source. Figure 13 shows the operating waveform of the drive power supply. $v_{\mathrm{cs}}$ is the voltage of sampling resistance $R_{\mathrm{cs}}, R_{\mathrm{cs}}$ is used to sample the current flowing through it. Figure 6a shows, when $M_{D}$ is turned on, the current of inductor $L_{D}$ flows through Rcs. $v_{g s}$ is the drive signal of $M_{D}$, and $v_{d s}$ is the voltage between drain and source of $M_{D}$. The circuit operates in a critical conduction mode, avoiding the loss caused by the reverse recovery of the body diode $\mathrm{D}_{1}$ of the upper MOSFET $\mathrm{M}_{1}$, and reducing circuit losses.

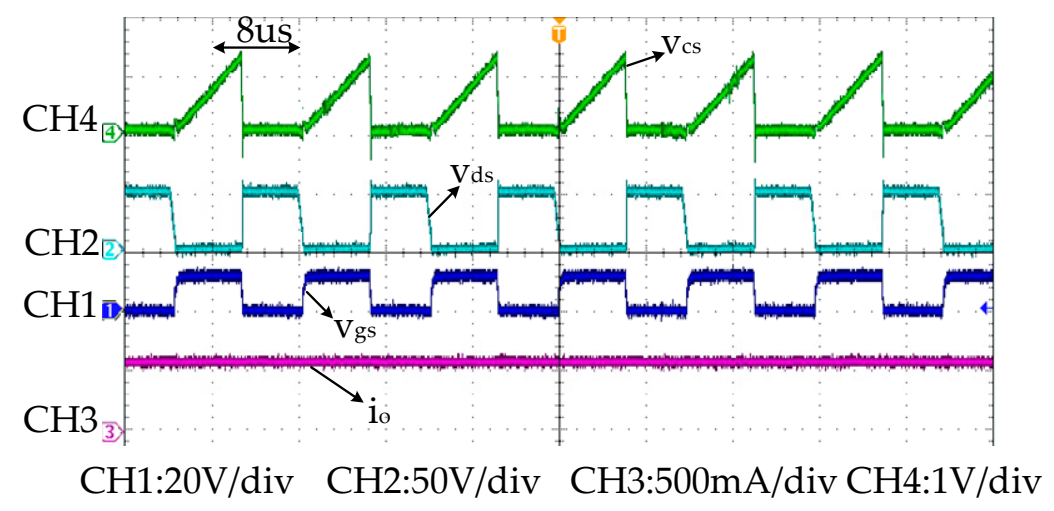

Figure 13. Critical conduction mode waveforms of distributed LED driver.

The LED driving power supply executes the command after demodulating the information on the DC bus. Figure 14 shows the waveform of the action performed after a drive power supply receives a light-off command. When the bus converter receives the command from the control center, it means to turn off the light, so that $\mathrm{v}_{\text {bus }}$ changes as shown in Figure 14, this signal represents the command 
"LED off at a certain address". Through the modulation and demodulation of the circuit, the signal is passed through the signal conditioning circuit to the LED driver at an address as shown in Figure 6a, so that it performs the light-off action, as shown in the CS waveform, and finally becomes a low level.



Figure 14. Execution command waveforms of distributed LED driver.

\section{Conclusions}

With common traditional lighting system remote control schemes like 0-10 V, PWM control, and DALI, two additional communication lines must be used, which brings installation inconvenience and costs more. Traditional PLC or wireless technologies do not need two communication lines. Although they are easy to install, they are not easy to popularize because of their high cost. A DC power grid based on the new power line carrier technology proposed in this paper enables the LED driving power source to have not only energy conversion capability, but also communication capability by using power electronics to realize communication technology. In order to realize the communication function of the driving power source, the proposed system includes a bus converter and a distributed driving power source. The bus converter modulates the information into the DC bus through variable modal control, from which the distributed drive power demodulates energy and information. In contrast with 0-10 V, PWM control, and DALI, this technology does not need communication lines, it is easier to install, and the cost is lower. Compared with the traditional PLC, its communication circuit is simpler, so the cost is lower. Compared with wireless technology, the radio frequency module can be omitted, so the cost is decreased and the installation is simpler. This technology not only simplifies the use of communication technology in application, but also reduces the difficulty of application. The prototype system validated the effectiveness of the technology. It is possible that this technology can also be used in other applications besides LED.

Author Contributions: Conceptualization, H.L. and J.H.; methodology, H.L.; software, H.L.; validation, H.L., J.H. and Z.L.; formal analysis, X.Z.; investigation, H.L.; resources, L.W.; data curation, J.H.; writing-original draft preparation, H.L.; writing—review and editing, H.L. and J.H.; visualization, H.L.; supervision, J.H.; project administration, Z.L.; funding acquisition, L.W.

Funding: This research was funded by National Natural Science Foundation Youth Project of China, grant number 51607060 .

Conflicts of Interest: The authors declare no conflict of interest. 


\section{Nomenclature}

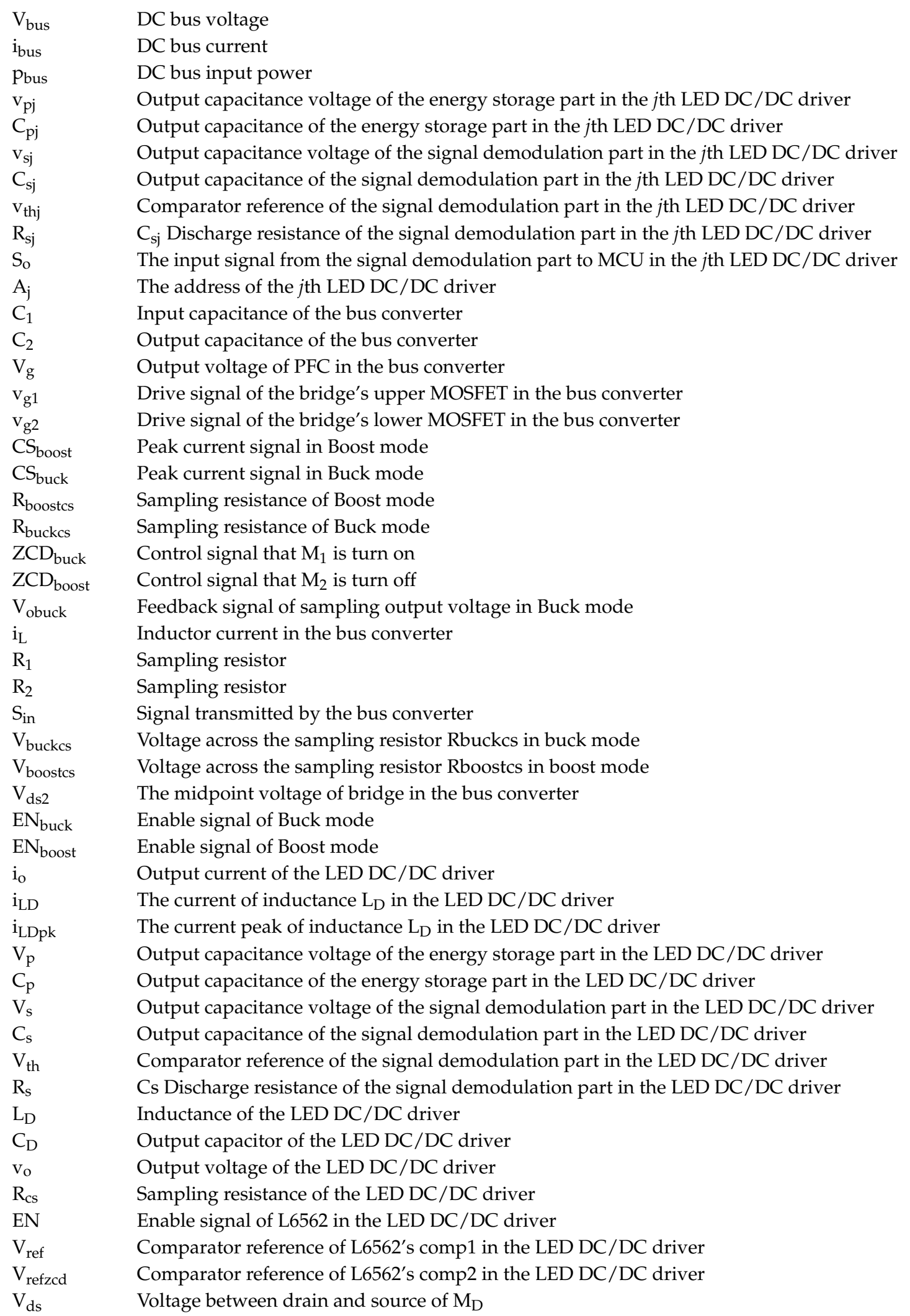




\section{References}

1. Yan, W.; Hui, S.Y.R.; Chung, H.S. Energy Saving of Large-Scale High-Intensity-Discharge Lamp Lighting Networks Using a Central Reactive Power Control System. IEEE Trans. Ind. Electron. 2009, 56, 3069-3078. [CrossRef]

2. Djuretic, A.; Kostic, M. Actual energy savings when replacing high-pressure sodium with LED luminaires in street lighting. Energy 2018, 157, 367-378. [CrossRef]

3. Beccali, M.; Bonomolo, M.; Leccese, F.; Lista, D.; Salvadori, G. On the impact of safety requirements, energy prices and investment costs in street lighting refurbishment design. Energy 2018, 165, 739-759. [CrossRef]

4. Jin, H.; Jin, S.; Chen, L.; Cen, S.; Yuan, K. Research on the Lighting Performance of LED Street Lights with Different Color Temperatures. IEEE Photonics J. 2015, 7, 1-9. [CrossRef]

5. Gentile, N.; Govén, T.; Laike, T. A field study of fluorescent and LED classroom lighting. Light. Res. Technol. 2016, 1-20. [CrossRef]

6. Fantozzi, F.; Leccese, F.; Salvadori, G.; Rocca, M.; Garofalo, M. LED Lighting for Indoor Sports Facilities: Can Its Use Be Considered as Sustainable Solution from a Techno-Economic Standpoint? Sustainability 2016, 8, 618. [CrossRef]

7. Perdahci, C.; Akin, H.C.; Cekic, O. A comparative study of fluorescent and LED lighting in industrial facilities. In Proceedings of the 2018 7th International Conference on Clean and Green Energy (ICCGE 2018), Paris, France, 7-9 February 2018.

8. Liang, Y.; Yimin, C.; Baorong, C. Integrated analog dimming controller for 0-10 V dimming system. In Proceedings of the 2013 10th China International Forum on Solid State Lighting (ChinaSSL), Beijing, China, 10-12 November 2013; pp. 147-149.

9. Dai, G.N.; Dai, B.L. Application of DALI Bus in Large High-end Lighting. Jiangsu Constr. 2016, 6, 113-115. [CrossRef]

10. Wang, S.; Liu, Y.; Yuan-Lin, C.; Jyun-Yan, C. Development of DALI-based electronic ballast with energy saving control for ultraviolet lamps. In Proceedings of the 2010 8th IEEE International Conference on Industrial Informatics, Osaka, Japan, 13-16 July 2010; pp. 214-219.

11. Bellido-Outeirino, F.J.; Flores-Arias, J.M.; Domingo-Perez, F.; Gil-de-Castro, A.; Moreno-Munoz, A. Building lighting automation through the integration of DALI with wireless sensor networks. IEEE Trans. Consum. Electron. 2012, 58, 47-52. [CrossRef]

12. Liang, T.J.; Huang, J.F.; Yadav, P.K. Design and implementation of dimmable LED control circuit with DALI protocol. In Proceedings of the 2016 IEEE International Conference on Power and Energy (PECon), Nice, France, 28-29 November 2016; pp. 121-126.

13. Wang, P. A Design of DALI Illumination System Based on RS-485. China Illum. Eng. J. 2012, 23. [CrossRef]

14. Khalilian, H.; Farzanehfard, H.; Adib, E.; Esteki, M. Analysis of a New Single-Stage Soft-Switching Power-Factor-Correction LED Driver With Low DC-Bus Voltage. IEEE Trans. Ind. Electron. 2018, 65, 3858-3865. [CrossRef]

15. Vallbè, B.; Balcells, J.; Bogónez-Franco, P.; Mata, J.; Gago, X. Immunity of power line communications (PLC) in disturbed networks. In Proceedings of the 2011 IEEE International Symposium on Industrial Electronics, Gdansk, Poland, 27-30 June 2011; pp. 1621-1625.

16. Han, R.; Yang, C.; Chen, X.; Han, X.; Zhang, J.; Li, C. Design of an Intelligent White-OLED Lighting System using power line communication. In Proceedings of the 2012 2nd International Conference on Consumer Electronics, Communications and Networks (CECNet), YiChang, China, 21-23 April 2012; pp. 3191-3194.

17. Beer, A.S.d.; Emleh, A.; Ferreira, H.C.; Vinck, A.J.H. Effects of LED lamps on the power-line communications channel. In Proceedings of the 2013 IEEE 17th International Symposium on Power Line Communications and Its Applications, Johannesburg, South Africa, 24-27 March 2013; pp. 209-213.

18. Amarsingh, A.A.; Latchman, H.A.; Yang, D. Narrowband Power Line Communications: Enabling the Smart Grid. IEEE Potentials 2014, 33, 16-21. [CrossRef]

19. Kubota, H.; Suzuki, K.; Kawakimi, I.; Sakugawa, M.; Kondo, H. High frequency band dispersed-tone power line communication modem for networked appliances. IEEE Trans. Consumer Electron. 2006, 52, 44-50. [CrossRef]

20. Mak, S.T. TWACS®, A Power Line Communication Technology for Power Distribution Network Control and Monitoring. IEEE Trans. Power Deliv. 1986, 1, 66-72. [CrossRef] 
21. Ferreira, H.C.; Grove, H.M.; Hooijen, O.; Vinck, A.J.H. Power line communications: An overview. In Proceedings of the IEEE AFRICON'96, Stellenbosch, South Africa, 27-27 September 1996; Volume 552, pp. 558-563.

22. Tan, Y.K.; Huynh, T.P.; Wang, Z. Smart Personal Sensor Network Control for Energy Saving in DC Grid Powered LED Lighting System. IEEE Trans. Smart Grid 2013, 4, 669-676. [CrossRef]

23. Cardesín, J.; García-Llera, D.; López-Corominas, E.; Calleja, A.J.; Ribas, J.; Gacio, D. Low cost intelligent LED driver for public Lighting Smart Grids. In Proceedings of the 2013 International Conference on New Concepts in Smart Cities: Fostering Public and Private Alliances (SmartMILE), Gijon, Spain, 11-13 December 2013; pp. 1-6.

24. Wu, J.; Li, C.; He, X. A novel power line communication technique based on power electronics circuit topology. In Proceedings of the 2010 Twenty-Fifth Annual IEEE Applied Power Electronics Conference and Exposition (APEC), Palm Springs, CA, USA, 21-25 Feberary 2010; pp. 681-685.

25. Lin, Z.; Du, J.; Wu, J.; He, X. Novel communication method between power converters for DC micro-grid applications. In Proceedings of the 2015 IEEE First International Conference on DC Microgrids (ICDCM), Atlanta, GA, USA, 7-10 June 2015; pp. 92-96.

26. Wang, R.; Du, J.; Hu, S.; Wu, J.; He, X. An embedded power line communication technique for DC-DC Distributed Power System based on the switching ripple. In Proceedings of the 2014 International Power Electronics and Application Conference and Exposition, Shanghai, China, 5-8 November 2014; pp. 811-815.

27. Du, J.; Wu, J.; Wang, R.; Lin, Z.; He, X. DC Power-Line Communication Based on Power/Signal Dual Modulation in Phase Shift Full-Bridge Converters. IEEE Trans. Power Electron. 2017, 32, 693-702. [CrossRef]

28. Wu, J.; Zong, S.; He, X. Power/signal time division multiplexing technique based on power electronic circuits. In Proceedings of the 2011 Twenty-Sixth Annual IEEE Applied Power Electronics Conference and Exposition (APEC), Fort Worth, TX, USA, 6-11 March 2011; pp. 1710-1714.

29. Li, C.; Wu, J.; He, X. Realization of a general LED lighting system based on a novel Power Line Communication technology. In Proceedings of the 2010 Twenty-Fifth Annual IEEE Applied Power Electronics Conference and Exposition (APEC), Palm Springs, CA, USA, 21-25 Feberary 2010; pp. 2300-2304. 